\title{
ARQUITECTURA Y REBELIÓN: CONSTRUCCIÓN DE IGLESIAS DURANTE LA REVUELTA DE ‘UMAR B. HAFȘŪN
}

\author{
Fernando ARCE SAINZ \\ CSIC. Madrid \\ «Modesta, rústica y patéticamente inacabada, la capilla \\ rupestre de Bobastro es, además, un símbolo histórico» \\ (J. Fontaine, El arte mozárabe, 1982, p. 65)
}

\section{INTRODUCCIÓN}

Desde hace bastantes años la revuelta de 'Umar b. Hafsūn posee un perfil historiográfico propio que, en el campo de la cultura material, se traduce en una serie de edificaciones religiosas cristianas que representan, prácticamente, los únicos gestos edilicios mozárabes ${ }^{1}$ reconocidos como tales. La circunstancia de la legendaria apostasía de Ibn Hafṣun y su consiguiente adopción de la fe cristiana marca una sustancial diferencia respecto a otros capítulos de la fitna que sacudió la última fase del emirato. La condición cristiana, aunque adquirida, del rebelde ha hecho pensar a muchos investigadores que el elemento mozárabe sería en verdad protagonista activo en la lucha y no un mero espectador al socaire de unos acontecimientos marcados por la confrontación entre poderes siempre musulmanes (muladíes, árabes, bereberes). Que el cabecilla más recalcitrante de la rebelión terminara por abrazar el cristianismo parece decir que, en primer lugar, el componente mozárabe implicado en la sedición tendría el

\footnotetext{
${ }^{1}$ Soy consciente de que la utilización del término mozárabe es objeto de discusión entre los investigadores, por lo que me veo en la obligación de aclarar cuál es la carga conceptual con la que voy a manejarlo, a fin de evitar interpretaciones erróneas. En el presente trabajo decir mozárabe equivale a decir cristiano que vive en territorio musulmán, sin ningún otro tipo de connotación. No es más que una acepción de un término que, nos guste o no, puede emplearse de forma diversa y nunca unánime. En el campo de la Historia del Arte, por ejemplo, prima actualmente la opinión de que el único arte al que se le puede llamar estrictamente mozárabe es aquel practicado por los cristianos que habitaron en al-Andalus, a los cuales no se ve impedimento en llamar mozárabes, según costumbre historiográfica. Al mismo tiempo, es poca la gente que sigue utilizando el término mozárabe para denominar al arte que tradicionalmente era conocido bajo este nombre de los primeros trabajos de Gómez-Moreno - el arte de la décima centuria de los territorios cristianos del norte - al haberse puesto en duda el protagonismo creativo de los cristianos procedentes del sur musulmán, a quienes, asimismo, también es tradicional llamar mozárabes. Me consta que en el terreno de los estudios árabes se ha llegado a conclusiones diferentes a las anteriormente expresadas respecto a la pertinencia del manejo del término, pero mientras no se produzca un debate en el que participen especialistas de todos los campos de la investigación histórica (historiadores, arqueólogos, historiadores del arte), no será raro que la palabra mozárabe siga siendo plural en su significado.
} 
suficiente peso como para que su pertenencia a él no fuera un menoscabo para la figura de Ibn Hafṣūn y, en segundo lugar, que a partir de la nueva condición cristiana del principal poder rebelde el elemento mozárabe vería reforzada su posición.

Siguiendo estos razonamientos se suele admitir un panorama especialmente propicio para un grupo social, el mozárabe, al que se le atribuye, en condiciones llamemos normales, un papel de minoría impuesto por el dominante poder musulmán. Entre las limitaciones que soportaron estaban las restricciones a la hora de expresarse monumentalmente mediante la construcción de edificios religiosos. Con unos cristianos dueños de su destino como los que se supone acompañaron a Ibn Hafṣun, no tuvo que haber en teoría impedimento alguno para que se levantaran iglesias de nuevo cuño. En este contexto de excepcionalidad, en el que no se reconoce ni la vigencia de un marco legal ni la eficacia de un aparato coercitivo que sujete a los mozárabes a la condición de minoría, se entendería que habría más posibilidades de encontrar manifestaciones artísticas cristianas en territorio musulmán.

\section{LA DEFINICIÓN DE UN ESTEREOTIPO ARTÍSTICO}

Hace algún tiempo pareció surgir una suerte de «arqueología hafṣuníi» de la mano, principalmente, de Puertas Tricas (1979, 1982, 1985a, 1985b, 1986, 1987, 1988) y Ríu $(1972,1974-1975,1980-1981,1981)$, que ha tenido por escenario algunas de las regiones inmersas en la rebelión. Si bien no se puede decir que estos acercamientos arqueológicos pretendieran identificar de forma indefectible ciertos objetos con la revuelta de Ibn Hafṣun, lo cierto es que ha habido una tendencia a entrelazar ambas realidades hasta hacerlas consustanciales. De estas exploraciones ha surgido el lote de iglesias al que nos referíamos en el párrafo introductorio. Puede llamar la atención que absolutamente todos los casos reunidos sean de naturaleza rupestre. Este hecho no debe explicarse como una casualidad, sino como resultado de las bases teóricas y metodológicas que han ido definiendo los elementos de adscripción que definen la cultura material de los mozárabes relacionados con la fitna.

Para poder comprender este proceso es necesario remontarnos a los albores de la historiografía moderna, justo al momento en el que por primera vez se asociaron restos materiales concretos al movimiento sedicioso. Debemos a F. J. Simonet (1983: 515, nota 1) la identificación física de Bobastro con los restos arqueológicos de Mesas de Villaverde (Málaga). Parece que la idea no es del todo original suya, ya que se refiere a un estudio más antiguo hecho por el mili- 
tar Serafín Estébanez (1849). Tampoco da la sensación de que hubiera recorrido personalmente el yacimiento, pues tras una somera descripción de los restos, en la que no reconocemos a la luego famosa iglesia rupestre, termina diciendo: «Debemos estas noticias á personas entendidas que han examinado el terreno» (515, nota 1$)$. De todas formas, fue la publicación de la noticia por parte de Simonet la que abrió el camino para futuras descubiertas sobre el terreno. De entre los edificios arruinados que se esparcían por el lugar, sin duda el más cercano a su original fisonomía era una estructura semirrupestre que a todas luces conformaba un templo cristiano. El hecho de que fuera una iglesia confería al hallazgo un enorme valor simbólico, muestra de la sincera conversión cristiana de Ibn Ḥafsūn y, con ella, de la legitimización de su lucha. La ruina alcanzaría la dimensión de icono cultural tras el estudio de Mergelina (1925), el primer autor en realizar un acercamiento propiamente arqueológico. $\mathrm{Al}$ interpretar una estructura tallada en la roca cercana al ámbito templario como la tumba en la que reposó el cadáver de Ibn Hafṣūn hasta la profanación de sus restos por las tropas cordobesas, se unía indefectiblemente a la iglesia con la figura del rebelde. La iglesia rupestre de Bobastro, al colocar tras ella al propio Ibn Hafșūn, quedaría como el ejemplo más representativo de lo que fue la actividad edilicia durante el período de la sedición. Su carácter troglodítico se aviene además con una imagen de montaraz resistencia que enlazaría con los ulteriores episodios de bandolerismo que tendrían lugar en esas serranías, dando lugar a la creación de románticas invariantes históricas (Dozy, 1881: 447-448; Suárez, 1975; Marqués de Lozoya, 1977: 279). La cita que encabeza este artículo, extraída de una obra de Fontaine, resume a la perfección esta mitificación del objeto arqueológico al considerarlo «un símbolo histórico» cuyo aspecto es poco menos que la transposición esculpida de unos dramáticos acontecimientos.

A pesar del indudable potencial arqueológico del pretendido Bobastro, no fue objeto de ningún nuevo trabajo original hasta la década de los setenta (Puertas Tricas, 1979). Esta aproximación se produjo en un contexto científico en el que el famoso estudio de Vallvé (1965) había puesto en duda que el lugar de Mesas de Villaverde fuera en verdad el solar donde se encontraba la capital rebelde. Puertas se hace eco del dilema planteado y se muestra siempre prudente a la hora de identificar lo que él estudia con la capital rebelde. Ante la duda, lo importante para él es saber si, a partir de un minucioso acercamiento a la realidad del edificio, se puede seguir defendiendo la posibilidad de que se trate de esfuerzo edilicio adscribible a las fechas de la fitna. El análisis tipológico, que sigue a lo ya expuesto por Mergelina, concluye afirmando que, efectivamente, esta iglesia, al margen de que estemos o no en Bobastro, pudo ser 
realizada al mismo tiempo que estas tierras estaban levantadas en armas. Esto significaba que los cristianos partícipes en la lucha en verdad generaron una cultura material de corte monumental que no tuvo por qué ser patrimonio de los impulsos personales de Ibn Ḥafșun. La iglesia de Mesas de Villaverde deja de ser vista como una «máscara de Agamenón» para convertirse en incuestionable canal de expresión artística de los mozárabes inmersos en la rebelión. Lo que quedaba inalterado, a pesar de que Puertas en ningún momento lo alentara, era un paisaje artístico rudo llamado a sobrevivir en momentos convulsos.

En años sucesivos, merced a la labor del propio Puertas $(1982,1986,1987$, 1988a, 1988b), se fueron sumando nuevos ejemplos de arquitectura rupestre atribuidos a los mozárabes: Pizarra, Coín, la Oscuridad y Nuestra Señora de la Cabeza en Ronda, Alozaina, Villanueva de Algaidas, Archidona. Sin duda, la técnica del vaciado de la roca en el caso más señero - Mesas de Villaverde- sirvió necesariamente como elemento de adscripción básico en el momento de proponer el mozarabismo del resto de casos estudiados, ya que, a excepción de Alozaina, no había contextos arqueológicos asociados ni características tipológicas extrapolables y comparables con los de la arquitectura propiamente construida. A pesar de estas dificultades, a menudo presentes en el análisis de estructuras troglodíticas, su atribución mozárabe ha sido aceptada sin demasiada crítica, fortaleciéndose esa identificación entre la revuelta de Ibn Ḥafsūn y las manifestaciones artísticas monumentales cristianas en forma de antros excavados.

La escasa prestancia artística de estos pseudoedificios fue tomada por ciertos investigadores de la Historia del Arte como un argumento más para defender el marasmo creativo de los cristianos que habitaron tierras musulmanas (Bango, 1996). Si unos mozárabes a los que se supone libres, por su insumisión frente a Córdoba, de las cargas restrictivas emanadas de la autoridad emiral no eran capaces de materializar sus aspiraciones de forma más airosa, habría que pensar que una secular inactividad impuesta condujo a una progresiva analfabetización artística en la que, llegado un ambiente propicio, ya no se fuera capaz de poner en marcha los resortes técnicos y materiales acordes con una edilicia monumental. Qué no sería de la calidad de los objetos producidos por los mozárabes sujetos a poderes musulmanes efectivos. Bango se esfuerza por demostrar que esas iglesias representan no un arte fruto y resultado de una coyuntura - la rebelión-, sino a las limitadas capacidades artísticas del colectivo mozárabe en general, independientemente de los contextos particulares. La sedición, a lo sumo, puso en evidencia las carencias monumentales cristianas. Lo que se valora es el resultado de la acción dentro de una lectura globalizadora de lo que significó la producción material cristiana en al-Andalus. Esta 
interpretación forma parte de un paradigma explicativo de la Alta Edad Media hispana en la que los mozárabes carecen casi por completo de cualquier impulso artístico. Cuando en casos excepcionales, como en la revuelta hafṣūní, pudieron tomar alguna iniciativa, saltaron a la vista sus limitaciones.

Tras todo lo visto parece que es poco más lo que se puede alcanzar a conocer sobre la materialidad de los mozárabes radicados en la serranía malagueña en el período temporal coincidente con la fitna. Así se percibe al menos en el campo de la Historia del Arte, la cual da por fehacientes y suficientemente expresivos los objetos tradicionalmente adscritos a este episodio, para terminar diluyéndolo todo en unas coordenadas históricas amplias que afectan a toda la cultura material mozárabe. Sin embargo, se aprecian lagunas teóricas y metodológicas que, tal vez, obligarían a dar nuevos enfoques al tema. Para empezar, no suele quedar claro si estamos hablando de la existencia de un arte mozárabe que tiene su razón de ser en la insurrección o de un arte que pudo producirse por los cristianos de esa zona al margen de que tuvieran lugar los violentos acontecimientos. Otro aspecto no bien resuelto es el saber si, efectivamente, las técnicas propias de la arquitectura rupestre son las que definen la actividad edilicia en ese momento y lugar. Por último, llama la atención el escaso uso que se hace de las fuentes escritas, siempre musulmanas, a pesar de la interesante información que suministran. A través de las mismas conocemos diferentes aspectos que rodean a la producción material de corte monumental en el seno de la rebelión que el presente paisaje artístico, representado por unas estructuras descontextualizadas, no parece refrendar más que de una forma parcial. Las noticias documentales, además, tampoco parecen traslucir esa idea de invariable baja calidad en las respuestas materiales mozárabes, a causa de una pretendida marginalidad social y económica en todo tiempo y lugar.

OBJECIONES AL ESTEREOTIPO, EL ANÁLISIS TEXTUAL

¿Podemos seguir diciendo que hay una serie de objetos artísticos que se explican en el contexto de la revuelta hafșūní o, por el contrario, su existencia responde a otros impulsos? Cuando Simonet «descubrió» Bobastro y Mergelina asoció la iglesia allí reconocible con Ibn Ḥafṣun, era evidente que se pretendía dar corporeidad arqueológica a un acontecimiento histórico y unos protagonistas especialmente sensibles para parte de nuestra historiografía más conservadora. Bastantes años más tarde, las objeciones de Vallvé a reconocer en Mesas de Villaverde el asiento de la capital sediciosa introdujeron elementos de duda que, sin embargo, no afectaron de forma sustancial a esa identifi- 
cación entre rebelión y construcción de iglesias. Ahí es donde se inscribe el trabajo de Puertas sobre Mesas de Villaverde: puede que no estemos en Bobastro, pero el templo allí encontrado puede ser perfectamente una iglesia «rebelde». Actualmente, la tesis de Vallvé no parece contar con mucho apoyo, siendo varias las objeciones que se le han hecho en los últimos años (Martínez Enamorado, 1996). De nuevo, la tradicional ubicación de Bobastro vuelve a tener aceptación, sin que esto signifique que las cosas vuelvan a encontrarse en el mismo punto que en tiempos de Mergelina. El cambio sustancial es que se ha dejado de especular sobre si fue o no Ibn Ḥafșūn el impulsor de la famosa iglesia. Lo importante es haber admitido que en verdad nos encontremos en el escenario real de los hechos. Por otra parte, los distintos análisis tipológicos referidos al edificio siempre lo inscriben en un horizonte cronológico postvisigodo por nadie cuestionado que perfectamente pudo coincidir con la Bobastro rebelde, circunstancia que fortalece la presunción. En conclusión, es muy plausible volver a reivindicar la idea de que coincidiendo con la rebelión se erigieron iglesias de nueva planta. Otra cosa será discernir el alcance de este hecho - saber si fue generalizado o puntual-e identificar a los promotores de las iniciativas, así como las razones que les animaron. ¿Quiénes y por qué, dentro del colectivo cristiano relacionado con la fitna, impulsaron la construcción de iglesias?

Para poder dar respuesta a estas cuestiones, hemos comprobado que el actual registro arqueológico se compone de un elenco de estructuras rupestres cuyo estudio siempre plantea serios problemas de adscripción fiables, debido a su propia naturaleza (Azkárate, 1988). Salvo el caso de Mesas de Villaverde, el resto de ejemplos están sujetos a una contingencia cronológica que relativiza bastante su valor testimonial. Con una información material todavía insuficiente nos queda, no obstante, el análisis textual como canal de penetración en el mundo material. Sin duda, lo ideal sería cotejar los datos documentales con los extraídos por medio de la arqueología, más aún cuando estamos en disposición de poder actuar en un escenario tan señalado como Bobastro. Por desgracia, lugares como éste se encuentran todavía mal conocidos, más allá de la resonancia mítica de su nombre (Martínez Enamorado, 1998).

Las fuentes que pueden arrojar alguna luz sobre la actividad edilicia en el marco de la revuelta están recogidas en crónicas árabes (manejamos los textos de Ibn Ḥayyān recogidos en el Muqtabis III y en el Muqtabis $V^{2}$ ), lo cual podría hacer pensar que estaríamos ante una información mediatizada por el discurso

\footnotetext{
2 Agradezco a Cristina de la Puente su ayuda para completar el aparato crítico de este artículo, ya que ha localizado en las fuentes árabes los textos en cuyas traducciones yo me he basado.
} 
ideológico de sus autores, que no fueron los sublevados, sino los pertenecientes al poder vencedor. Este hecho es indudable, pero tendremos que ver, con las debidas prevenciones, hasta qué punto aquellos datos que nos dan cuenta de posibles empresas constructivas son más o menos reveladores. Más importante que este aspecto es no perder de vista la simplificación de los cronistas árabes al narrar los acontecimientos (Acién, 1994: 64), que siempre tendrán como protagonistas a los personajes de las clases dirigentes envueltas en la lucha. Esto significa que poco o nada conoceremos de las iniciativas de la mayor parte de la base social, algo, en definitiva, nada extraño en la inmensa mayoría de la documentación histórica medieval.

En relación a uno de estos personajes importantes, las fuentes árabes mencionan al padre de Ibn Ḥafșun, Ḥaf̣, como promotor de un templo cristiano en las inmediaciones de Bobastro: «Destruyó [Mutarrif] todo lo que había en su derredor [de Bobastro], incluso la huerta de al-Munya, de propiedad de Ibn Ḥafșunn, y que se hallaba en el lugar llamado al-'Armāt. Cuando el ejército real comenzó a devastar la huerta, el faccioso [Ibn Ḥafșūn] salió con sus renegados a defenderla y a impedir que se dañara una iglesia contigua, que fuera edificada por Ḥafș, su maldito padre» (Muqtabis III, ed. árabe, p. 108; trad. XXVXXVI, pp. 335-336). El ejército cordobés consiguió su destructor objetivo arrumbando el templo, del cual ya no volveremos a saber nada en siguientes narraciones. ¿Quedó la iglesia destruida por siempre o se reparó? A los problemas que plantean las fuentes antes mencionadas, habría que sumarles su carácter episódico en situaciones de este tipo. De repente, nos dan a conocer un dato del que desconocemos antecedentes y consecuentes. En el que ahora nos ocupa, no obstante, quedan claros algunos importantes hechos: que Hafṣ patrocinó la construcción de una iglesia y que ésta se levantaba en una propiedad perteneciente a su familia.

Estaríamos, en apariencia, ante una iniciativa de carácter eminentemente privado. El templo se levanta en una almunia que sería el presumible lugar de residencia del promotor. Convendría superar la tradicional visión historiográfica que focaliza la atención en el propio gesto edilicio de Hafṣ como indicio de su conversión al cristianismo y la influencia que este hecho tendría en su hijo. Sin negar la relevancia de este asunto, también se hace interesante el tratar de conocer si lo que está haciendo Hafș es una mera acción piadosa o responde a un modelo de actuación sociopolítico y cultural concreto dentro de las sociedades envueltas en los conflictos de la fitna. Nada nos dice, por otra parte, que la iglesia hubiera sido levantada al hilo de los enfrentamientos, tan sólo que fue destruida durante ellos. Esto obliga a plantearnos nuevos interrogantes: ¿por qué un personaje perteneciente a un poder local muladí que, por otro lado, no 
parece que termine por abrazar el cristianismo (Acién, 1994: 88), auspicia la construcción de una iglesia?; ¿es un caso aislado y excepcional o se trata de un comportamiento habitual que, además, no tiene que estar supeditado a la existencia del enfrentamiento con el poder emiral?

Siguiendo con las noticias recogidas en las fuentes musulmanas, no volveremos a encontrar otra tan explícita como la anterior en lo referido a la construcción de iglesias. Sin embargo, los datos suministrados por los cronistas árabes son lo suficientemente elocuentes como para pensar que la iniciativa de Hafs no fue un hecho aislado. Al margen de los motivos y necesidades que llevaron a Hafs a emprender esta acción, encontramos a otros grupos de poder con capacidad e intenciones para ofrecer también sus propias respuestas monumentales. Conviene recordar que en el núcleo dirigente de la sedición aparece la figura de un jerarca eclesiástico, un obispo, directamente vinculado a la figura de Ibn Hafṣūn. El mitrado más destacado, aunque no el único, que vivió en Bobastro, fue Ibn Maqsim. Con la información que tenemos no podemos saber con seguridad si el obispo de Bobastro era, en realidad, el que ocupaba la cátedra de Málaga o se llegó a instaurar una pseudosede independiente que vendría a reforzar la imagen de la autoridad rebelde. Parece más probable la primera opción, pero hay ciertas actuaciones que conducirían a favorecer, con el tiempo, lo segundo. Ibn Hafșūn aparece deponiendo y promocionando obispos de forma directa, lo que indica, de algún modo, estar atribuyéndose esa antigua prerrogativa del poder temporal de época visigoda —que tendría su prolongación en el mundo musulmán- que permitió, primero a los reyes toledanos y luego a los emires cordobeses, intervenir en el estamento religioso mediante la convocatoria de concilios y la confirmación de obispos. De todos modos, cuando Ibn Hafsūn desaloja a Ibn Maqsim de su cargo nombrando a un sustituto cuyo nombre ignoramos, la presión de un sector de los cristianos obligó a restituirle en el puesto: «... cuando Ibn Hafṣūn lo destituyó del obispado [a Ibn Maqsim], al cabo de un tiempo, queriendo menoscabar su categoría y nombrando a otro para relegarlo, los monjes y ancianos cristianos le obligaron a confiarle su gobierno y hubo de hacerlo obispo al poco...» (Muqtabis V, ed. árabe, p. 114; trad., p. 95). Venga o no venga de Málaga el obispo de Bobastro, es evidente que su suerte ha quedado desvinculada del organigrama eclesiástico general. Tiempo después, Ŷa 'far, hijo de Ibn Hafṣun, también ejercerá su autoridad para decidir sobre la suerte del obispo, que seguía siendo Ibn Maqsim: «... y tendió [ Ŷa 'far] al obispo Ibn Maqsim la asechanza de que algunos malvados diáconos y enemigos del califato proclamaban contra él razones suficientes para su impugnación y deposición del episcopado, con lo que lo depuso, castigó y expulsó de su capital a un monasterio, donde estaba vigilado, 
nombrando en su lugar a otro» (Muqtabis V, ed. árabe p. 140; trad., p. 114). Al parecer, la más alta jerarquía religiosa envuelta en los acontecimientos mostró una actitud de mediación en el conflicto que, en ciertos momentos, chocó abiertamente con la postura de la clase dirigente. Por esta razón se producen enfrentamientos que se traducen en las deposiciones obispales, siempre relacionadas con Ibn Maqsim, a quien los cronistas árabes reservan, no por casualidad, palabras de elogio. No es raro que se produjera esta sintonía entre el obispo y el poder emiral, ya que en situaciones de paz amparada por los pactos ambos salían beneficiados. Recordemos ciertas medidas adoptadas por un obispo como Hostegesis, malacitano para más señas. Al actualizar durante su mandato el censo de los cristianos, no sólo está ayudando al fisco musulmán —razón por la que fue denostado por alguno de sus coetáneos como el abad Sansón y una moderna historiografía reaccionaria-, sino que también está asegurando el mantenimiento de la diócesis.

La existencia de este obispado en Bobastro, más allá de los conflictos internos en los que aparece mezclado, indica representatividad y organización, un elemento cristiano jerarquizado en el seno de la rebelión. Por tanto, no es aventurado suponerle capacidad de actuación en el terreno de la dotación de espacios representativos. Es cierto que siempre nos quedará la duda de que las iglesias que se levantaban en Bobastro y sus alrededores, cuando las tropas cordobesas conquistan la plaza, pudieran ser más antiguas. Tal vez no fue necesario erigir ningún templo, conformándose con las viejas iglesias y apropiándose y transformando mezquitas abandonadas. Si las fuentes nada aclaran respecto a la modernidad de las iglesias, tampoco dicen nada de que fueran anteriores. En cuanto al tema de las mezquitas, es, en cambio, muy seguro que allí donde cesó la función religiosa musulmana no vino a suplantarla la cristiana: «Fue ['Abd al-Raḥmān III] a su mezquita más antigua [de Bobastro], que estaba abandonada» (Muqtabis V, ed. árabe, pp. 165-166; trad., p. 216); «La plegaria se hizo en nombre de al-Nāṣir en la abandonada mezquita de Bobastro... poblándose allí las abandonadas mezquitas...» (Muqtabis $V$, ed. árabe, p. 217; trad., p. 167). ¿Se conformarían los cristianos exclusivamente con los templos heredados del pasado? No lo creemos. Sirviéndonos de nuevo del análisis textual encontramos referencias a iglesias que ocupan lugares eminentes dentro del enclave rebelde: «... y destruyéndose las cuidadas iglesias cuya excelente construcción y proximidad al palacio del maldito 'Umar, junto al descuido de las mezquitas y su abandono y ausencia de cuidados, habían sido los más sólidos indicios de la apostasía del maldito 'Umar» (Muqtabis V, ed. árabe, p. 217; trad., p. 167). Aparte de esta centralidad, también hay noticias que nos hablan de la dispersión de edificios de culto en los alrededores de 
Bobastro. En una de las aceifas anteriores a la rendición de la ciudad, cuenta Ibn Ḥayyān: «En el combate fueron derrotados los renegados y quemadas las alquerías y las suntuosas iglesias que se levantaban en las inmediaciones de Bobastro» (Muqtabis III, ed. árabe, p. 352; trad., XXIX-XXX, p. 352). ¿Son equiparables estas iglesias a la que hizo levantar Hafṣ en su alquería? Las noticias no acaban aquí. Conocemos, a su vez, un monasterio en las cercanías de Bobastro: «Sulaymān [hijo de Ibn Ḥafșūn] se alegró de su alejamiento [de las tropas cordobesas], hasta tal punto que un día cabalgó fuera de la ciudad, para ir a beber [entendemos que vino] a un monasterio de la aldea de Canales...» (Muqtabis V, ed. árabe, p. 206; trad., p. 159). De nuevo llamamos la atención sobre la imposibilidad de saber cuántos de estos edificios eran preislámicos o simplemente anteriores a la revuelta, pero también reiteramos nuestra extrañeza de que, entre tanto, como se menciona, no haya nada posterior a 711 .

Como se ve, no hay menciones expresas, salvo la de Ḥafs, a los promotores de estos esfuerzos edilicios. Ya hemos apuntado como posible auspiciador de empresas constructivas al aparato eclesiástico presente en Bobastro; pero ¿qué pasa con los poderes laicos encabezados por el propio Ibn Ḥafșun? Las fuentes no atribuyen a éste ninguna construcción de oratorios cristianos. Tan sólo conjeturan como prueba de su apostasía con la calidad y proximidad de algunas iglesias respecto a su palacio. Que Ibn Ḥafṣun hubiera auspiciado la erección de alguna iglesia es algo que no podemos saber, aunque tampoco sería algo extraño. En los inicios de la rebelión, Ibn Ḥafșūn patrocinó la construcción de una mezquita aljama en Bobastro. Este gesto reafirma su poder, haciéndole aparecer como protector e impulsor de la religión, al dotar a la comunidad con un lugar de culto principal. La mezquita en cuestión no sobrevivió a la piqueta de las tropas cordobesas, por considerarla un impío monumento inspirado por un falso musulmán: «Luego ordenó ['Abd al-Raḥmān III] destruir la mezquita aljama que el maldito 'Umar b. Ḥafsūn se había hecho al principio de su rebelión para engañar a los perversos musulmanes que le acompañaban... de modo que fue arrasado y quemado el mimbar desde donde se había bendecido al apóstata y su perversa estirpe» (Muqtabis $V$, ed. árabe, p. 219; trad., p. 168). ¿Volvería Ibn Ḥafșūn a dar muestras de este evergetismo pero en una vertiente confesional cristiana?

Por otra parte, tenemos a destacados personajes dentro de la revuelta vinculados a la figura de Ibn Ḥafșun. Entre ellos, los hay descendientes de las antiguas clases dirigentes y otros que, sin un pasado relevante, consiguen promocionarse en el transcurso de los acontecimientos (Acién, 1994: 88-91). Como dice este mismo autor, las empresas edilicias que emprenden los jerarcas de la revuelta son fundamentalmente de carácter militar, pero también hay palacios, 
casas, almacenes e ¿iglesias? Parece lógico pensar que el rebelde o rebeldes con capacidad e intenciones para levantar iglesias serían partícipes de la fe cristiana. Esta premisa, no obstante, no queda clara en el ejemplo de Ḥafs, tal como ya quedó dicho, por lo que no hay que descartar otras acciones muladíes en este sentido. De todas formas, son bastantes los $a s ̣ h a ̄ b$ cristianos vinculados a Ibn Ḥafṣun, tanto en la misma Bobastro como en diferentes ḥuṣunn diseminados por el territorio de la küra de Rayya. En Bobastro y sus alrededores ya se ha mencionado un número de iglesias indeterminado, pero no desdeñable. De aquellos lugares en los que la autoridad estaba en manos directas de los $a s ̣ h a ̄ b$-dependientes también tenemos algunas noticias que hablan de la existencia de iglesias. Durante la toma de Dos Amantes, se dice: «Se acogieron [los sitiados], pues, a la alta alcazaba, mientras el ejército incendiaba el arrabal y las iglesias que allí tenían» (Muqtabis V, ed. árabe, p. 149; trad., p. 120). La caída del enclave de Torrox se acompañó igualmente con la destrucción de edificios, algunos religiosos: «Sus alcazabas fueron derruidas, desmantelados los muros y arrojadas sus piedras al río, ordenándose construir en lugar de su iglesia una mezquita aljama» (Muqtabis V, ed. árabe, p. 172; trad., p. 135). Estos asentamientos - llamados por Acién ummahāt al-ḥusūn y ḥusūun complejos por la historiografía francesa (Cressier, 1984) - tendrían su razón de ser en el contexto de la fitna (Acién, 1994: 85). De ser esto así, habría que considerar a la misma Bobastro como un lugar surgido en época islámica, de tal forma que los diferentes complejos constructivos de los que nos dan cuenta los textos serían siempre postvisigodos, al margen de que algunos fueran o no erigidos durante los años en los que el conflicto fue más virulento. Acién no duda en considerar a Bobastro una «empresa» de Ibn Ḥafșūn (Acién, 1994: 85), frente a otras opiniones que sitúan su origen en fechas preislámicas (Gozalves, 1989: 222). Los argumentos que se esgrimen para defender esta cronología preislámica se refieren a diferentes hallazgos procedentes del lugar de Mesas de Villaverde: dos inscripciones «cristiano-visigodas» que fueron llevadas al museo arqueológico de Granada (Rodríguez de Berlanga, 1903: 176); un anillo de bronce con una inscripción que alude a un obispo de época visigoda (Vives, 1969: n. 397) y otros objetos inéditos, como una moneda del Bajo Imperio y un fragmento de inscripción de tradición cristiana (Gozalves, 1989: 222). Hoy por hoy, estos datos arqueológicos tienen un valor bastante relativo debido a su total descontextualización, lo que no quiere decir que carezcan de valor. Mientras no se acometan verdaderas campañas excavatorias en este yacimiento, no estaremos en disposición de solucionar el problema en torno a su nacimiento. Si el resto de los husụun de mayor importancia tienen también su razón de ser en los acontecimientos que se producen a lo largo del siglo IX, hemos de sospechar que las 
iglesias allí presentes - ¿todas, algunas? - serían de esas fechas. Mientras que en Bobastro encontramos tanto iglesias como mezquitas, en otros lugares sólo se documenta la presencia de espacios cultuales cristianos, dándose a entender que la población residente era toda o casi toda mozárabe, incluyendo a la clase dominante. Así lo corroboran los siguientes pasajes textuales: «Todos sus habitantes eran cristianos, sin un solo musulmán, y lo mismo la fortaleza de Comares ya mencionada y sus hermanas Santopitar y Š.d.līa, pues las fortalezas de aquella zona habían sido de los cristianos desde siempre» (Muqtabis $V$, ed. árabe, p. 223; trad., p. 171); «Desde la colina en que acampaba el ejército prosiguió su marcha y avanzó hacia la fortaleza [el castillo de Ibn Jașib en Monte Moro], cuyos defensores, que celebraban el día de Pentecostés, salieron de noche y se trabaron en lucha encarnizada» (Muqtabis III, ed., árabe, p. 119; trad., XXVII, p. 169).

Lo que se quiere demostrar con esta lectura de los textos es la existencia de un paisaje edilicio que no se corresponde con el actual registro arqueológico ni puede explicarse desde esa pretendida marginalidad y escasa relevancia de la producción monumental mozárabe.

\section{UNIDAD O DIVERSIDAD EN LAS RESPUESTAS MATERIALES MOZÁRABES}

Tras haber realizado este repaso por las fuentes escritas, se puede decir que la idea de unos cristianos levantiscos, tallando rudas iglesias, parece muy simplificadora. Sin negar que se dieron casos de arquitectura rupestre - ahí está la iglesia de Mesas de Villaverde-, nada indica que fuera una práctica edilicia generalizada derivada de una incapacidad. El más que probable enclave en el que se levantaba Bobastro cuenta con varias muestras de este tipo de técnica constructiva, pero junto a ellas hay estructuras aéreas faltas de exploración que nos están hablando de unos parámetros arquitectónicos distintos. La presencia de canteras de las que extraer materiales es una muestra más de la puesta en marcha de recursos edilicios típicos de la arquitectura exenta. Lo que se constata entonces es que, en el lugar que pudo ser el más significativo de la rebelión, se combinaron diferentes técnicas constructivas, entre las que se incluía la rupestre. A partir de esta afirmación, es aventurado dar explicaciones en cualquier sentido sin antes dar respuesta a varios interrogantes: ¿La utilización de técnicas rupestres se enmarca en el contexto edilicio imperante o surge de manera coyuntural?; ¿es mayoritaria su presencia?; ¿qué conocemos en cantidad y en calidad de esa otra arquitectura propiamente construida?; ¿el ejemplo de la supuesta Bobastro sirve para conocer lo que ocurrió en otros lugares? 
Todas estas preguntas son las que en un futuro deberemos responder para poder conocer de forma más precisa lo que significó la actividad constructiva en esta región durante las últimas décadas del emirato, más allá del hecho de la confesionalidad de sus protagonistas. Lo lógico es pensar que estos mozárabes invertirían los recursos técnicos y formales imperantes en el contexto material que les rodeó, el mismo que informaría la construcción de los edificios coetáneos, desde las mezquitas hasta las residencias urbanas o campestres, pasando por las fortificaciones. Se podría decir en contra que tal vez los cristianos, en su condición de minoría — social, no numérica-, dentro de una sociedad controlada por poderes musulmanes, pudieron experimentar un secular desgaste que les dejaría en una situación de desventaja a la hora de expresarse monumentalmente, por lo que la posibilidad de acceder a ciertos recursos creativos había quedado ya fuera de su alcance. De esta forma, su producción material se movería por la senda de la marginalidad, incluso cuando la situación les fuese ventajosa. Ignoramos cuál fue el marco de relaciones entre cristianos y musulmanes en esta zona tras la conquista musulmana, pero sí sabemos que en el momento de producirse la fitna el elemento mozárabe no se revela como un grupo social inmerso en un proceso de inexorable debilitamiento impuesto desde fuera, sino más bien como un colectivo sujeto a condicionantes tanto externos como internos, similares a los que tienen que ver con el resto de las fuerzas implicadas, en especial la muladí. Esto no quiere decir que las cosas se hayan mantenido inalterables como si nada hubiera pasado. Por supuesto que la conquista musulmana ha significado cambios en el espacio político, social y económico de la población autóctona, pero el colectivo mozárabe presenta todavía una complejidad interna que no puede entenderse desde la perspectiva de una homogeneización consumada que les llevara a expresarse materialmente de forma unitaria, porque todos comparten una misma condición. Lo que nos dicen las fuentes y la arqueología es que las respuestas serían diferenciadas dependiendo de las capacidades y aspiraciones de un colectivo, el cristiano, al que lo único que le da unidad es el componente religioso. Sabemos, por ejemplo, que hay poderes cristianos que son capaces de articular un territorio con sus habitantes no como resultado derivado estrictamente de la rebelión, sino siguiendo una práctica que puede tener su origen mucho más atrás. Recordemos las palabras de Ibn Ḥawqal al referirse a ciertos cristianos de zonas rurales que evocan comportamientos repetidos durante la revuelta: «Hay en España más de una explotación que agrupa a millares de campesinos que ignoran todo de la vida urbana y son europeos de confesión cristiana [...]. Cuando se sublevan se atrincheran en un castillo» (ed. árabe, p. 111; trad., p. 63). Lo que este autor musulmán nos está describiendo son grupos de cristianos que siguen manteniendo estructuras organizati- 
vas y productivas de origen preislámico, con poder y capacidad para imponerse y organizar a una población dependiente. Al mismo tiempo, conocemos por la arqueología un tipo de asentamientos, los hușūn refugio, que comenzaron a surgir en época visigoda y que, tras la conquista islámica, se acrecientan (Acién, 1993). Se trata de poblamientos en altura de carácter campesino, escasamente jerarquizados socialmente, ubicados en pequeños enclaves mejor o peor defendidos cuya base económica es la explotación de los recursos inmediatos, sin que se pueda vislumbrar una generación de excedentes. Este carácter autosuficiente y autónomo parece aludir a una situación bastante distinta a la antes mencionada por Ibn Ḥawqal, en la que una población más o menos amplia está vinculada a un poder que cuenta con los resortes necesarios para ejercer su posición de dominio. No sería necesario irse fuera del contexto más directo de la rebelión para analizar distintas realidades sociales en las que aparecen implicados cristianos. Junto a los ḥuṣūn refugio encontramos a los antes mencionados ḥuṣūn complejos, entre los que habría que incluir a Bobastro, que se convierten en centros dominadores del territorio y asiento de los poderes que ejercen su control y organización. Allí es, por otra parte, donde las fuentes señalan la existencia de las distintas iglesias y, también, no lo olvidemos, de las mezquitas, los palacios, las fortalezas, etc. Digo esto porque los huṣūn complejos, al igual que ocurre con los husūun refugio, que, con el tiempo, fueron sometidos a los primeros, no son por definición cristianos. Algunos están dominados por poderes cristianos y otros por poderes musulmanes, pero todos responden a unas mismas pautas históricas en las que el elemento mozárabe no puede entenderse de manera aislada. En resumidas cuentas, lo que tenemos es un panorama social diverso, en el que las respuestas materiales cristianas estarán definidas por las capacidades, limitaciones e intereses de los distintos agentes actuantes dentro del colectivo mozárabe, un cuerpo socioeconómico en absoluto homogéneo, como tampoco lo son el muladí, el árabe o el bereber.

\section{Tradición o inNovación, el caso de la iglesia de Mesas de Villaverde EN EL MARCO DE LA ARQUITECTURA ALTOMEDIEVAL}

Un último aspecto que nos gustaría abordar es el de la caracterización artística de los objetos producidos por estos mozárabes. Saber si las herramientas técnicas y estéticas empleadas se pueden considerar como propias de una tradición antigua - al igual que ocurre con los sistemas sociales y productivos cuyo origen es preislámico - o bien pertenecen a un universo creativo surgido tras la conquista musulmana que, aunque asimile elementos locales, tiene sus 
principales bases formativas en repertorios extrapeninsulares (Caballero, 19941995). Se trata, al fin y al cabo, de un capítulo más del debate sobre la pervivencia y el cambio del bagaje cultural hispano tras la aparición y el afianzamiento del mundo islámico en la Península, tema candente en el actual panorama de la investigación medieval (Mérida, 1999). Desde hace unos cuantos años lo mozárabe apenas tenía cabida en esta discusión porque se consideraba que su presencia, artísticamente hablando, era episódica y marginal, en tanto en cuanto unas restrictivas disposiciones impuestas por los poderes musulmanes habían impedido a los cristianos de al-Andalus acometer empresas constructivas monumentales en forma de iglesias de nueva planta. Los escasos ejemplos de los que hablan las fuentes y el paupérrimo elenco arqueológico considerado mozárabe (lápidas funerarias, algún objeto metálico, un puñado de libros miniados y, cómo no, las iglesias rupestres) se convertían en argumentos para defender esta teoría. Sin embargo, en los últimos tiempos, tanto el análisis textual como la arqueología están relativizando esta visión restrictiva. Un conocimiento cada vez más profundo de la realidad mozárabe está demandando huir de respuestas unívocas que no tienen en cuenta la multitud de factores que intervienen y que definen escenarios claramente diferenciados (Arce, 1992; Cruz, 1994-1995; Real, 1995). De esta manera, se están vislumbrando situaciones específicas en las que los cristianos aparecen protagonizando de forma bastante inequívoca esfuerzos edilicios que superan los límites de la marginalidad, lo cual no quiere decir que estemos pasando a una postura diametralmente opuesta a la anterior, siguiendo un movimiento pendular, sino que se están descubriendo demasiadas excepciones a la regla que obligan a buscar respuestas más complejas y matizadas. De lo que se trata es de aproximarnos a estas situaciones para intentar explicarlas materialmente a la luz de su contexto histórico, antes de hacer valoraciones de carácter general sobre lo que significó la práctica artística de los mozárabes a lo largo de un período de varios siglos.

Hemos visto que el presente trabajo se refiere a una de estas situaciones. Las fuentes árabes relacionadas con los conflictivos acontecimientos de la fit$n a$ nos hablan de edificios religiosos cristianos con muchas posibilidades de no ser preislámicos y tras los que encontramos grupos de poder mozárabes con capacidad e interés para emprender acciones de este tipo. Si los mozárabes están protagonizando iniciativas monumentales, cabe entonces preguntarse sobre la naturaleza de los modelos empleados en el sentido expresado más arriba: ¿qué pueden tener de perduración, transformación o cambio respecto a la tradición anterior a 711? Antes de seguir desarrollando este punto, una advertencia. Estamos todavía lejos de conocer con solvencia esta realidad material 
intuida por los textos ante la falta de información de carácter arqueológico, por lo que sólo podemos manejar por el momento un número limitado de objetos cuya interpretación, sea en el sentido que sea, adolecerá de contingencia a la espera de contar con nuevos datos. Por cierto, este desconocimiento afecta también a las empresas edilicias musulmanas de los siglos viII y IX. Sólo hay que recordar el panorama creativo que actualmente se atribuye al emirato, reducido inexplicablemente a un puñado de edificios: la mezquita de Córdoba y alguna que otra construcción militar.

Entre este limitado elenco tenemos a la tantas veces nombrada iglesia de Mesas de Villaverde, único ejemplo arquitectónico religioso conocido con relación, por todos admitida, con las fechas en las que se inscribe la revuelta. Por ahora tendremos que conformarnos con el estudio de este edifico postvisigodo para intentar alcanzar a comprender los derroteros por los que se movía la edilicia mozárabe en esas fechas y regiones. El asunto de la pervivencia/innovación, en términos materiales, se tendrá que dirimir en la discusión de varios aspectos como son el técnico, el formal, el planimétrico. El primero de ellos, el técnico, plantea ciertos problemas que ya han quedado expuestos con anterioridad. La técnica empleada, la rupestre, aparte de que no sabemos hasta qué punto es representativa en el contexto creativo general, nada puede aportar sobre otros recursos propios de una arquitectura exenta, desde el tipo de materiales que se podían emplear (piedra, ladrillo, morteros, madera), hasta la forma de aparejarlos en muros y cubiertas. No obstante, ya que en nuestra iglesia hay visos de reproducir lo que sería un edificio «construido», contamos con elementos singulares y planimétricos que sí pueden servir a nuestros intereses. De hecho, ha sido un elemento singular, el arco de herradura conservado, el que se ha esgrimido como argumento tipológico de peso para defender su mozarabismo. Las proporciones de su peralte (más de $2 / 3$ de radio, Mergelina, 1925: 12), al ser cotejadas con una tipología definida por la historiografía, que se convirtió poco menos que en canónica (Gómez Moreno: 1906; Camps Cazorla, 1963; Caballero, 1977-1978), eran más características en los arcos de herradura islámicos que en sus precedentes visigodos, menos ultrapasados $(1 / 3 \mathrm{del}$ radio). Hoy día este argumento sigue dándose como fiable, en tanto en cuanto las propuestas de los viejos maestros no han sido puestas en cuestión. No seremos nosotros quienes lo hagamos, ni éste el lugar en el que hacerlo, pero no estaría de más que en el futuro inmediato se volviera a reflexionar sobre este elemento convertido en definitorio de nuestra arquitectura altomedieval, cristiana y musulmana. En primer lugar hay serias dudas sobre la cronología de algunos de estos arcos, en especial los que serían representativos de la fase visigoda, lo que haría que la secuencia cronotipológica tal vez no sea correcta. 
Siendo estrictos, los arcos de herradura que están fechados con total certeza parten del siglo VIII en la mezquita de Córdoba y continúan en los siglos IX y X, tanto en la edilicia musulmana como en las iglesias llamadas mozárabes por Gómez Moreno. El único caso que parecía fiable para tiempos visigodos, San Juan de Baños, merced a la celebérrima inscripción de mediados del viI, se ve envuelto en la sombra de la duda al descubrirse de forma incontrovertible que hay piezas «visigodas» reutilizadas en la iglesia, por lo que nada asegura que la lápida esté datando la construcción del edificio (Caballero y Feijoo, 1998). No se hagan valoraciones interpretativas apresuradas de todo lo que se acaba de decir, porque en ningún momento se está defendiendo una propuesta distinta a la tradicional. Tan sólo se pretende sacar a la luz nuevos problemas planteados que deberán ser resueltos, bien para reafirmarse en la teoría consensuada, bien para modificarla.

Estas llamadas a revisar algunos aspectos generales en torno a la definición histórica de este elemento arquitectónico no pretenden relativizar las clásicas valoraciones respecto al caso específico de Mesas de Villaverde. Junto al desarrollo acusado del peralte - característica que tenemos bien documentada en ejemplos del siglo IX y sobre todo del $\mathrm{X}$ - hay otros detalles en su composición que también abogan por defender unas fechas similares. Nos referimos a la forma cóncava de su intradós, práctica a la que no se le encuentra una explicación clara —para avivar las aristas, en opinión de Gómez Moreno (1919: 153)—, que se repite en edificios como Escalada, Wamba, Lebeña, Celanova y la mezquita del Cristo de la Luz, todos levantados en la décima centuria.

Dentro del apartado planimétrico y espacial, nuestra iglesia también ha permitido ir a la búsqueda de paralelos «construidos» en los que poder enmarcarla históricamente, algo que casi es imposible hacer en los otros ejemplos rupestres que se piensa pudieron ser realizados durante la revuelta (Coín, Archidona, Ronda, etc.). Se compone el templo de tres ámbitos bien diferenciados: una cabecera con tres espacios absidales adyacentes - la del centro, en planta de herradura, sin duda el presbiterio-, un cuerpo basilical formado por tres naves $\mathrm{y}$, entre medias de las zonas absidal y congregacional, un transepto tripartito que une ambas partes, pero que queda de algún modo aislado, al estrecharse deliberadamente los pasos que lo comunican con una y otra zona, al tallarse una suerte de canceles faltos de decoración. Sin embargo, esta proyección plana que ofrece un modelo muy coherente, no debe hacernos olvidar un hecho manifiesto en el alzado que siempre ha planteado problemas interpretativos. Nos referimos a la notable mayor altura a la que se encuentra la nave $S$ respecto a la central y la $\mathrm{N}$, circunstancia que ha llevado a pensar en una obra inacabada. Lo que parece lógico es que se hubiera continuado el vaciado hasta el 
nivel del suelo de las naves, para así conseguir un típica estructura basilical. ¿Era ésta en verdad la intención de los constructores, y por alguna razón fue necesario variar el proyecto? Ésta es la opinión más generalizada. Puertas Tricas dice que es necesario distinguir entre «las medidas teóricas de la iglesia y las medidas reales» (Puertas, 1979: 180), por la dificultad del tallado en la roca de todo un edificio, al no poderse hacer rectificaciones. Por esta misma razón, Gómez Moreno afirma que la iglesia no se pudo concluir, porque la roca era insuficiente para albergar una fábrica del tamaño deseado y, además, iba mal planteada (Gómez Moreno, 1951: 335). Mergelina comparte esta idea y redunda en la no finalización del trabajo, encontrando además lo que en su opinión sería la interrumpida labor de vaciado, representada por un hueco rectangular tallado en la nave $\mathrm{S}$, dentro de un procedimiento «que se seguiría para vaciar la peña, y que debió de consistir en excavar a tramos pequeños, que se terminaban totalmente antes de emprender un nuevo corte» (Mergelina, 1925: 168). Fontaine, en cambio, achaca la inconclusión a razones totalmente ajenas al proceso constructivo. Imagina que los cristianos se vieron obligados a interrumpir su labor cuando la plaza se rindió a las tropas cordobesas (Fontaine, 1988: 64-65).

Salvo este investigador, en coherencia con su explicación, el resto de estudiosos no dudan de que la iglesia funcionó como tal o, lo que es lo mismo, se dio por buena la obra pese a su insatisfactorio remate. El desnivel de alturas, por tanto, es habitualmente achacado a un accidente antes que a una intención deliberada. Se crea así un espacio elevado ciertamente anómalo, sin ningún paralelo conocido en la arquitectura altomedieval peninsular. Su rareza, que no se amolda con la idea de espacios elevados como las tribunas - siempre a los pies y enfrentada al presbiterio, como en las iglesias asturianas (a excepción del caso dudoso de Santullano [García de Castro, 1995: 462]) y en San Baudelio de Berlanga-, encuentra una buena justificación en esa diferencia entre lo pensado y lo efectuado de la que nos hablaba Puertas. El resultado ciertamente pudo ser fruto de las circunstancias, pero hay algunos aspectos que no parecen hijos del azar. El caso es que la nave $\mathrm{S}$ no se encuentra «colgada» respecto al resto de la iglesia, sino que el espacio que le precede en el transepto, así como el ábside que está a continuación, están igualmente más altos que sus adyacentes, conformando los tres ámbitos un nivel coherente independiente del resto. Efectivamente, el suelo sigue el mismo escalonamiento observado en los otros dos ejes E-O, con el ábside en el nivel superior seguido por el transepto y éste, a su vez, más alto que la nave, gradación que al parecer nada tiene que ver con posibles irregularidades en la peña, sino con una intención buscada. Escalonamientos de este tipo, probablemente relacionados con planteamientos de 
carácter simbólico, están documentados en iglesias del siglo X, como Santa María de Lebeña (Fontaine, 1988: 65). En resumidas cuentas, se organiza la sucesión de espacios de una manera idéntica al resto del edificio, con la diferencia de que se encuentran sensiblemente más altos. Da la sensación de que esta intención es la que rige el trabajo desde el principio y que no hubo cambio de planes, ya que, como dice Puertas, el vaciado de la roca no permite rectificaciones, por lo que parece mucha casualidad que, en el momento de reconducir el proyecto, los tres niveles pudieran ser ordenados de forma totalmente satisfactoria, reproduciendo el escalonamiento del resto del edificio. Es posible que el determinismo impuesto por la mole rocosa marcara, antes de empezar a vaciar, el proyecto a ejecutar, el cual no sería otro que el que podemos ver, obligando a dejar en alto la zona meridional. En esta parte tenemos la mayor potencia del bloque pétreo, por lo que llevar la altura de la zona $\mathrm{S}$ hasta la del resto de la iglesia habría supuesto, aparte de un trabajo más arduo, «calar» en la roca una arquería de cierta entidad, labor comprometida debido a los grandes vanos que se debían abrir. ¿Tenemos que seguir apelando a limitaciones impuestas por el enclave elegido para explicar un resultado arquitectónico que nos resulta extraño? Desde luego, es lo más cómodo, pero no está del todo claro. Una vez tallada la roca, el resto del edificio se elevaría mediante muros realizados seguramente en mampostería, por ser de más fácil adaptación a las superficies irregulares generadas. La cubierta que remataría la fábrica se supone de madera, pero no sería descartable un abovedamiento también de mampuesto si nos fijamos en el aljibe subterráneo de Marmuyas, el yacimiento que se propuso como alternativa a la ubicación de Bobastro tras los trabajos de Vallvé (Riu, 238). Se trata de un depósito de agua parcialmente tallado entre dos rocas, y con muros y bóveda de argamasa y piedras. El aljibe se compone de 9 compartimentos abovedados dispuestos en tres naves comunicados por arcos de herradura bastante ultrapasados, semejantes a los de Mesas de Villaverde. Lo que queremos destacar en esta comparación es la combinación de técnicas a la hora de acometer una construcción como muestra de un universo tecnológico complejo que no se reduce a intentos más o menos afortunados en el vaciado de la roca.

El análisis de la planta del edificio, excusada la contradicción de la altura de toda la parte meridional, permite contar con elementos de contraste que sí podemos rastrear en el universo edilicio altomedieval conocido. Sin pretender ser exhaustivo, aquí van algunas de las sugerencias comparativas manejadas: la acusada herradura del ábside central —que no se desarrolla en altura, sino que al llegar a cierta altura se modifica para hacerse de planta cuadrada (Puertas, 1979: 84) - recuerda presbiterios paleocristianos como los de Marialba, Cabeza de Griego y Leiría en Portugal, y también mozárabes, como Pedret y 
Escalada (Mergelina, 1925: 169-170); la cabecera triple con un ábside central curvo flanqueado por otros rectangulares aparece en la basílica paleocristiana de Son Bou (Fontaine, 1988: 65); los muretes que separan los distintos espacios deben considerarse auténticos canceles, mobiliario litúrgico con gran presencia en la arquitectura peninsular; con la disposición basilical de las naves pasa lo mismo: el esquema general de la planta tiene bastantes semejanzas con San Miguel de Escalada (Mergelina, 1925: 13; Puertas, 1979: 203; Fontaine, 1988: 65).

En este complejo mundo de las analogías, en el que no es fácil distinguir lo que es parecido de lo que es paralelo, se tiende a diluir lo visto en Mesas de Villaverde en un amplísimo marco histórico-artístico supuestamente homogéneo plagado de soluciones y experiencias que se repiten en distintos momentos y lugares: «Esta tipología planimétrica, aunque con ciertas irregularidades debidas a las dificultades de la labra de la roca, corresponde en todos los detalles a modelos perfectamente documentados en edificios hispanos construidos desde la época paleocristiana hasta el mismo siglo XI» (Bango, 1991: fichero, n..$^{\circ}$ ). Admitiendo sin duda que muchos de los elementos configuradores del espacio de la iglesia malagueña — sobre todo cuando los aislamos- están también presentes en otros edificios con fechas dispares, queda por saber si son tradicionales dentro del contexto arquitectónico en el que surgen o bien si dicho contexto, en general, es conservador y, por tanto, genera objetos tradicionales. Contamos con una importante traba a la hora de enmarcar históricamente nuestra iglesia, porque carecemos, en al-Andalus, de información material sobre otros edificios mozárabes que pudieran servir de comparación. Esto hace que se empleen como elementos de contraste ejemplos edilicios que se encuentran en los reinos cristianos, pero son cercanos a la cronología propuesta. A pesar de las prevenciones que esta limitación impone, todos estamos de acuerdo en admitir que hay importantes concomitancias arquitectónicas entre Mesas de Villaverde y algunas de las llamadas iglesias mozárabes por unos y de repoblación por otros. Ya se han ido exponiendo las distintas analogías que confieren un grado de familiaridad que no parece casualidad. Las conclusiones a las que podemos llegar al ver que Bobastro, pese a su aparente marginalidad, no desentona con iglesias muy lejanas geográficamente, pueden ser todo lo dispares que queramos. Los, llamemos, mozarabistas (Gómez Moreno, Mergelina, Fontaine), veían plenamente confirmada su teoría al comprobar cómo una iglesia levantada por cristianos andalusíes (Bobastro) contenía algunos rasgos definitorios de los edificios que otros mozárabes emigrados al norte construirían más adelante. Para los, digamos, visigotistas (Camón Aznar, Bango), en cambio, es una muestra de cómo pasadas experiencias preislámicas seguían tenien- 
do vigencia siglos después tanto en las tierras septentrionales como en las meridionales, separadas y enfrentadas en lo político, pero con rasgos culturales comunes, mucho más cuando nos referimos al colectivo mozárabe como descendiente de la población autóctona hispanovisigoda.

Ya asumamos uno u otro modelo explicativo, se coincide en admitir que el arte mozárabe o de repoblación tiene una serie de rasgos distintivos que conforman un sistema técnico y formal original. A nadie se le ha ocurrido defender una cronología que no fuese mozárabe en la iglesia de Bobastro ante la presencia de ese aire familiar que la emparenta, sin forzar las comparaciones, con los edificios más emblemáticos conservados de la décima centuria. Teniendo en cuenta que nuestra iglesia rupestre está tratando de reproducir modelos construidos, tenemos que admitir que en al-Andalus se están levantando edificios en el siglo IX que no son confundibles con la tradición considerada visigoda (La Nave, Bande, Melque, Quintanilla, etc.), pero que, en cambio, muestran similitudes con las fábricas erigidas en el siglo siguiente en bastantes zonas de la Meseta Norte. Por ahora, ofrecemos sin más esta sugerencia de debate, en un nuevo intento por poner de manifiesto las contradicciones que encierran los distintos paradigmas. En el discurso de los mozarabistas en la línea de Gómez Moreno es difícil comprender cómo muchos de los objetos paradigmáticos del arte que llaman mozárabe son anteriores a la existencia misma del califato, a cuyo amparo nació el motor creativo del que son deudores. En cuanto a la postura visigotista de apelar a una koiné artística hispana desde época tardoantigua hasta la llegada de las formas románicas como explicación totalizadora, deja en el aire cuestiones como la antes expuesta: que en Mesas de Villaverde y en los territorios cristianos se esté llegando a soluciones semejantes, pese a su alejamiento, cuando la pretendida inercia tradicional, además, se nos muestra cambiante en su devenir histórico, si comparamos lo visigodo, lo asturiano y lo de repoblación.

La originalidad de lo ejecutado en Bobastro dependerá de la originalidad que atribuyamos a lo que se está haciendo en al-Andalus en época emiral en relación al pasado preislámico. Como estamos hablando de arquitectura religiosa, se puede entender que los cristianos perseverarían en modelos antiguos, más que nada porque los musulmanes no construían iglesias que sirvieran de referente o influencia. Sin embargo, cuando nos referimos a las mezquitas, en concreto a las dos primeras fases de la mezquita cordobesa, se suele decir que su materialización no podría entenderse sin el concurso de la tradición arquitectónica local, a pesar, lógicamente, de que los cristianos hispanovisigodos jamás habían visto ni hecho antes ninguna mezquita. ¿Una nueva contradicción? Fijémonos en el caso de Bobastro. Tal como hemos visto, existían en este 
lugar varias mezquitas, siendo una de ellas iniciativa del propio Ibn Hafṣun. Los musulmanes que acometen estos esfuerzos, habida cuenta del entorno en el que nos movemos, parecen ser muladíes o, lo que es lo mismo, descendientes islamizados de la población anterior al 711. Cuando estos musulmanes construyen oratorios, acudirían a los repertorios técnicos y tipológicos imperantes, a no ser que terminemos por descubrir que las mezquitas muladíes se diferencian de las árabes y las bereberes por cuestiones etnoculturales. Dentro de ese mismo ambiente arquitectónico, encontramos a unos mozárabes, descendientes asimismo de los hispanovisigodos, construyendo iglesias. Nada impide suponer que acudirían a los mismos repertorios técnicos que los manejados por los musulmanes (árabes, bereberes o muladíes), pues cualquier recurso de estas características es aconfesional. Un muro compuesto por tal o cual material y aparejado de esta o aquella manera puede servir igual en una iglesia que en una mezquita o en un edificio civil. Lo mismo ocurre con ciertos repertorios decorativos.

En definitiva, la clave para poder decir si la iglesia de Bobastro es o no producto de la pervivencia o el cambio, pasa por seguir discutiendo sobre la caracterización de una amplia secuencia arquitectónica que iría desde la época visigoda hasta la implantación del románico, con especial atención a lo que supuso la producción material en al-Andalus, auténtico nudo gordiano del debate en curso.

\section{BIBLIOGRAFÍA}

ACIÉN, M., 1993: «La islamización del SE de al-Andalus. Los datos arqueológicos», Aculturazione e mutamenti. Prospettive nell'archeologia medievale del Mediterraneo, Siena.

—, 1994: Entre el Feudalismo y el Islam. 'Umar Ibn Hafșūn en los historiadores, en las fuentes y en la historia, Jaén.

ArCe SaInZ, F., 1992: «Los monasterios de Tábanos y Peñamelaria a la luz de los textos y su entorno histórico», Boletín de Arqueología Medieval, 6, 157-170.

AZKÁrATE, A., 1988: Arqueología cristiana de la Antigüedad Tardía en Álava, VitoriaGasteiz.

BANGO, I., 1989: Alta Edad Media. De la tradición hispanogoda al románico, Madrid. —, 1991: «El Arte Mozárabe», Cuadernos de Arte Español, n. ${ }^{\circ}$ 2, Madrid.

—, 1995: «El Arte Mozárabe», Congreso Nacional de Cultura Mozárabe, Córdoba, 37-52.

CABAllero, L., 1977-1978: «La forma de herradura hasta el siglo viII y los arcos de herradura de la iglesia visigoda de Santa María de Melque», Archivo Español de Arqueología, 50-51, 323. 
—, 1994-1995: «Un canal de transmisión de lo clásico en la Alta Edad Media española. Arquitectura y escultura de influjo omeya en la Península Ibérica entre mediados del vIII e inicios del X», Al-Qanțara, 15-16, 321-348 y 107-124.

Caballero, L., y Fejoo, S., 1998: «La iglesia altomedieval de San Juan Bautista en Baños de Cerrato (Palencia)», Archivo Español de Arqueología, 71, 81-242.

CABAllero, L., y Mateos, P. (coord.) (en prensa): Simposio Internacional, 1999: Visigodos y omeyas. Un debate entre la Tardoantigüedad y la Alta Edad Media, Mérida, 21 al 23 de abril de 1999.

CAMÓN AzNAR, J., 1963: «Arquitectura española del siglo X», Goya, 1963, 206-219.

CAMPS CAZORLA, E., 1963: Módulo, proporciones y composición en la arquitectura califal cordobesa, Madrid.

CRESSIER, P., 1984: «Le château et la division territoriale dans l'Alpujarra médiévale», Mélanges de la Casa de Velázquez, XX, 115-144.

Cruz Villalón, 1994-1995: «Badajoz visigodo, Badajoz mozárabe», Anas, 327-342.

Dozy, R, 1849: Recherches sur l'histoire et la littérature de l'Espagne pendant le Moyen $\hat{A} g e$, Leiden.

EstéBANEZ CALDERón, S., 1849: «De la milicia de los árabes en España», Revista Militar, T. IV, XXXII, 32-38.

FonTAINE, J., 1982: El arte mozárabe, Madrid.

GARCÍA DE CASTRO, C., 1995: Arqueología cristiana de la Alta Edad Media en Asturias, Oviedo.

Gómez Moreno, M., 1903: «Excursión a través del arco de herradura», Cultura Española.

—, 1919: Iglesias Mozárabes, Madrid.

—, 1951: «Arte Mozárabe», Ars Hispaniae, III, Madrid.

GoZÁLVES, C., 1989: «Nuevos yacimientos mozárabes en la provincia de Málaga», Boletín de Arqueología Medieval, 3, 221-232.

IBN HAWQAL, 1971: Configuración del mundo, trad. de M. ${ }^{a}$ J. Romaní, Valencia.

IBN ḤAYYĀN: Al-Muqtabis III, Chronique du règne du calife Umaiyade Abd Allah à Cordue. Texte arabe publié pour la première fois d'après le manuscrit de la bodlêienne avec une traduction par le P. Melchor Martínez Antuña, París, 1937, trad. de J. E. Guráieb, «AlMuqtabis de Ibn Hayyān», Cuadernos de Historia de España, XIII-XXXII, 1949-1960, XIII, 157-176; XIV, 174-182; XV, 157-169; XVI, 146-149; XVII, 155-166; XVIII, 152160; XIX, 155-164; XX, 155-164; XXI-XXII, 329-344; XXII-XXIV, 334-347; XXVXXVI, 334-342; XXVII, 164-172; XXVIII, 166-173; XXIX-XXX, 338-354; XXXIXXXII, 316-321.

-: Al-Muqtabas V, (ed.) P. Chalmeta, F. Corriente y M. Subh, Madrid 1979, (trad.) M. ${ }^{2}$ J. Viguera y F. Corriente, Crónica del califa Abdarraḥmān III al-Nāṣir entre los años 912 y 942 (al-Muqtabis V), Zaragoza, 1981.

LozoYA, M. de, 1977: Historia de España, Barcelona. 
MartíneZ ENAMORADO, V., 1995: «Algunas consideraciones espaciales y toponímicas sobre Bobastro», Al-Qantara, XVII, fasc. 1, 59-77.

—, 1997: «Bobastro (Ardales, Málaga): una madīna para un rebelde», Qurțuba, II, 123-147.

—, 1998: «Arqueología de los mozárabes. Bobastro (Málaga)», Revista de Arqueología, 202, 42-53.

MERGELINA, C. de, 1925: «De arquitectura mozárabe: la iglesia rupestre de Bobastro», Archivo Español de Arte y Arqueología, 2, 159-176.

PUeRTAS TRICAS, R., 1979: «La iglesia rupestre de Mesas de Villaverde. El Chorro (Málaga), Mainake, I, 179-216.

-, 1982: Un asentamiento mozárabe en la zona de Alozaina, Málaga.

-, 1985a: «Dos nuevas iglesias rupestres medievales en Málaga», I Congreso de Arqueología Medieval Española, Huesca, 360-372.

—, 1985b: «Dos iglesias rupestres mozárabes en Ronda (Málaga)», Cuadernos de la Alhambra, 21, 67-77.

—, 1986: «Los conjuntos rupestres mozárabes de Coín y Archidona», Cuadernos de la Alhambra, 22, 11-47.

_, 1987: Memoria preliminar de la II Campaña de excavaciones arqueológicas de 1987 en las Mesas de Villaverde (Ardales, Málaga), II Actividades sistemáticas, Anuario Arqueológico de Andalucía, 371-374.

—, 1988: «Iglesias rupestres de Ronda», Estudios de Ronda y su serranía, 1, 181-194.

REAL, M. L., 1995: «Inovação e resistência: dados sobre a antiguidade cristã no ocidente peninsular», IV Reunió d'Arqueologia Cristiana Hispànica (Lisboa, 1992), 17-68.

RIU, M., 1972: «Cuevas, eremitorios y centros cenobíticos rupestres en Andalucía oriental», VIII Congreso de Arqueología Cristiana, Barcelona-Roma, 1969, 431-443.

—, 1974-1975: «Poblados mozárabes de al-Andalus. Hipótesis para su estudio. El ejemplo de Busquistar», Cuadernos de Estudios Medievales, II-III, 3-35.

—, 1980-1981: «Marmuyas, sede de una población mozárabe en los Montes de Málaga», Mainake, II-III, 235-257.

_, 1981: «Consideraciones sobre la cuarta campaña arqueológica realizada en 1979 en el cerro de Marmuyas (Montes de Málaga)», Al-Qanțara, II, 229-249.

—, 1985-1986: «El gran aljibe subterráneo de Marmuyas (Comares, Málaga)», Estudios de Historia y Arqueología Medievales, V-VI, 345-360.

Rodríguez de Berlanga, M., 1903: Catálogo del Museo Loringiano, Málaga.

SIMONET, F. J., 1983: Historia de los mozárabes de España (reed.), Madrid.

SUÁREZ, L., 1975: Historia de España Antigua y Media, t. 1, Madrid.

VALLVÉ, J., 1965: «De nuevo sobre Bobastro», Al-Andalus, XXX, 139-174.

VIVES, J., 1969: Inscripciones cristianas de la España romana y visigoda, Barcelona. 


\section{RESUMEN}

Se plantea en este trabajo una revisión de la revuelta hafṣūní en su vertiente material, tradicionalmente identificada con un tipo de iglesias rupestres que han terminado por configurar un estereotipo artístico. A través de un repaso por las ideas que han ido definiendo este paisaje monumental y una lectura de las escasas fuentes arqueológicas y documentales existentes, se pretende demostrar que la actual interpretación no explica de forma satisfactoria lo que pudo representar la construcción de iglesias en el contexto de la fitna.

\section{ABSTRACT}

This article considers a revised interpretation of the Hafsununid revolt in its material aspect, traditionally identified with a type of cave church which has ended in forming an artistic stereotype. Through a review of the ideas which have defined this monumental landscape and a reading of the scant archeological and documentary sources, the article attempts to show that the present interpretation does not satisfactorily explain what the construction of churches in the context of the fitna could represent. 